\title{
A Study of the Frequency of Self-Mutilation in a Community Sample of Adolescents
}

\author{
Shana Ross ${ }^{1}$ and Nancy Heath ${ }^{2}$
}

Received July 21, 2000; accepted June 12, 2001

Currently little research exists examining self-mutilation (SM) in community samples of adolescents, despite tentative findings suggesting that self-harming behaviors, including SM may be increasing. The present study provides a comprehensive review of previous literature on the frequency of SM as well as preliminary epidemiological data concerning the frequency of SM in a community sample of high schools students. The relationship between SM, anxiety, and depressive symptomatology was also assessed. Four hundred and forty students from two schools, an urban and a suburban high school, were given a screening measure designed to assess for SM. Students who indicated that they hurt themselves on purpose also participated in a follow-up interview. Based on interviews it was found that $13.9 \%$ of all students reported having engaged in SM behavior at some time. Girls reported significantly higher rates of SM than did boys (64 vs. $36 \%$, respectively). Self-cutting was found to be the most common type of SM, followed by self-hitting, pinching, scratching, and biting. Finally, students who self-mutilate reported significantly more anxiety and depressive symptomatology than students who did not self-mutilate. Results are also presented concerning demographic information and patterns of SM behavior.

KEY WORDS: self-mutilation; self-harm; adolescents; anxiety; depression.

\section{INTRODUCTION}

The topic of self-mutilation (SM) has been gaining widespread attention in the mainstream culture (Favazza, 1998). Despite the current interest in the subject, little empirical research has been generated examining this phenomena. Much of the research consists of case studies (Lena and Bijoor, 1990; Solomon and Farrand, 1996) and when studies have been conducted, the majority have employed clinical samples of individuals with personality

The current study is part of a doctoral thesis and was supported by the Social Sciences Research Council of Canada.

${ }^{1}$ Doctoral candidate in the Department of Educational and Counseling Psychology at McGill University. Received MA in School Psychology from McGill University. Research interests include self-mutilation and depression in children and adolescents.

${ }^{2}$ Associate Professor in the Department of Educational and Counseling Psychology at McGill University. Research interests include depression, self-perception, and learning disabilities in children. To whom correspondences should be addressed at McGill University, Department of Educational and Counseling Psychology, 3700 McTavish Street, Montreal, Quebec, Canada H3A 1 Y2. disorders and other psychiatric problems making the results difficult to generalize to more normative populations (Burgess, 1991; Dulit et al., 1994; Ennis et al., 1989; Herpetz, 1995). Thus, little is known about SM in community samples of adolescents. Furthermore, there is some tentative evidence suggesting that the incidence of selfmutilative behavior may be increasing among adolescents (Hawton and Fagg, 1992). Given the lack of information concerning SM in community samples of adolescents, the goal of the current study is to investigate the frequency of SM in a sample of high school students and to examine related mental health problems such as anxiety and depression.

\section{Definitions of SM}

Defining SM has proven to be a difficult task for researchers and clinicians. There is no generally agreed upon terminology and a variety of terms have been described in the literature. The term SM (Brodsky et al., 1995; Favazza, 1998; Favazza and Rosenthal, 1993) is 
used interchangeably with terms such as self-injurious behavior (Herpertz, 1995; Shearer, 1994; Solomon and Farrand, 1996), deliberate self-harm (DSH; Pattison and Kahan, 1983; Patton et al., 1997; Taiminen et al., 1998), parasuicide, and self-wounding (Brooksbank, 1985; Tantum and Whittaker, 1992). The terms self-harm and SM have described adolescents who have attempted suicide, adolescents who have been referred to emergency rooms after self-injuring, and adolescents who have deliberately hurt themselves but do not express suicidal intent (Brittlebank et al., 1990; Hawton et al., 1997; McLaughlin et al., 1996; Scott and Powell, 1993). The distinction between these subgroups is critical given the bulk of research findings which indicate that SM and suicidal attempts are distinct and have different etiologies (Favazza, 1989; Solomon and Farrand, 1996; Winchel and Stanley, 1991). Thus, inconsistencies in definitions of SM have been further complicated by those studies, which have placed these subgroups together. This practice has made it difficult to obtain accurate estimates of the prevalence of SM.

\section{SM in Adolescence}

Although the general consensus in the literature is that SM begins in early adolescence (Favazza, 1998; Favazza and Rosenthal, 1993; Pattison and Kahan, 1983), few studies exist directly examining adolescent populations. While statements have been made in the academic literature and in the popular media that rates of SM appear to be on the rise (e.g., Pipher, 1994), there is little solid epidemiological data on the frequency and demographic variables. The literature investigating SM in adolescents can be grouped into 4 categories according to the methodology employed: (a) studies that have explored the frequency of self-harm behaviors in high school students, (b) studies that have examined adolescents admitted to emergency rooms, (c) studies that have investigated psychiatric inpatient adolescents, and (d) studies that have looked at a wide age range including adolescents.

In terms of the 1 st group of studies, none could be found focusing on the frequency of SM among high school students. Rather the majority of studies have investigated suicidal behaviors with the secondary goal of looking at self-harm behaviors, including SM. Patton et al. (1997) examined both suicidal behavior and patterns of self-harm in a community sample of Australian adolescents. Using items from the Beck Suicide Intent Scale (Beck et al., 1974), 1699 Australian students aged 15-16 years old were asked if in the last year, they had deliberately hurt themselves or had done anything that they knew would have harmed or killed them. Eighty-six participants reported a clear episode of deliberate self-harm, which corresponded to a 12-month prevalence estimate of $4.0 \%$ for males and $6.4 \%$ for females. The overall prevalence estimate for the population was $5.1 \%$. Females reported significantly higher rates of self-harm than did males. Self-laceration and deliberate recklessness were the most common types of self-harm. True suicide attempts were by comparison less common and were only reported by 1 in 200 adolescents. Similarly, Martin et al. (1995) examined the relationship between suicidal thinking, deliberate self-harm, and family functioning in Australian adolescents. Three hundred and fifty-two students $(n=$ 201 males; $n=151$ females) aged $15-16$ years old were asked to respond to questions regarding suicidal intent including a question designed to tap into self-harm (i.e., I deliberately try to hurt myself). Results indicate that $8.9 \%$ of students claimed that they had deliberately tried to hurt themselves. No significant gender differences were found ( $9 \%$ of females versus $8 \%$ of males).

In contrast to the above studies that have explored self-harm behaviors, including SM in adolescents, Favazza et al. (1989) investigated the prevalence of SM in a sample of university students. The Self-Harm Behavior Survey, a 178 item self-report questionnaire was administered to 245 undergraduates ( $n=172$ female, $n=$ 73 male) enrolled in an introductory psychology class. SM was defined as deliberate alteration or destruction of body tissue (Favazza, 1989). The authors found that 21 females $(12 \%)$ and 13 males $(18 \%)$ reported a history of $\mathrm{SM}$. The total prevalence of SM in the sample was estimated to be $13.8 \%$. In addition, in females, SM episodes varied considerably from only a few to a "great many number" (p. 355). No information was given concerning the number of self-mutilative episodes in males. While these findings are informative, the study was limited to adults and older adolescents and it is not known whether similar results would be found in samples of high school students. Thus, accurate rates of SM in populations of adolescents have not been obtained.

The 2nd group of studies examining adolescents who self-mutilate consists of individuals who have been referred to an emergency room following an episode of self-injury. Hawton et al. (1996) investigated deliberate self-poisoning and self-injury in children and adolescents under 16 years of age from 1976 to 1993. The study consisted of all individuals aged 16 and under who were referred to the general hospital because of self-injury and/or self-poisoning. Self-injury was defined as any "injury recognized by hospital staff as having been deliberately self-inflicted" (p. 203). Seven hundred and fifty-five individuals were involved in 854 episodes of deliberate 
self-harm. An increase was noted in the proportion of individuals who reported previous episodes of self-harm from $13.0 \%$ in $1976-81$ and $12.7 \%$ in $1982-87$ to $25.8 \%$ in 1988-93. This increase was more common for girls. However, the vast majority of episodes $(96.5 \%)$ involved self-poisoning. Similarly, Hawton and Fagg (1992) examined deliberate self-poisoning and self-injury in adolescents aged 10-19 from the years 1976-89. The authors found that out of all the patients referred to emergency services for self-harm, $25.5 \%$ were adolescents. Adolescents aged 10-14 years old comprised $3.2 \%$ of the cases referred for DSH while adolescents between 15 and 19 years of age comprised $22.3 \%$. Finally, in a study examining problem-solving, hopelessness, depression, and deliberate self harm, McLaughlin et al. (1996) administered the Suicide Intent Scale to 51 adolescents aged 12-16 years ( $n=41$ females; $n=10$ males) who had overdosed (DSH group). Results indicate that $13 \%$ of the DSH group had previously self-harmed. These studies suggest that selfharming behavior may be increasing among adolescents. However, because many of the participants were referred to emergency rooms for a variety of self-harming behaviors, including suicide attempts and drug overdoses, it is important to investigate the occurrence of SM in a normative sample.

The 3rd group of studies, although limited in number, have been conducted on clinical samples of adolescents. Only one study directly tested the prevalence of $\mathrm{SM}$ in a clinical group of adolescents. The remainder of the studies have focused on characteristics of adolescents who self-mutilate (e.g., Walsh and Rosen, 1988; Rosen et al., 1990). Schwartz et al. (1989) examined self-harm, specifically self-laceration, in a sample of female adolescent drug abusers who were attending an outpatient drug treatment program. A 30-item questionnaire was completed by 85 girls of which 41 were identified as "self carvers" without suicidal intent. The authors found that $43 \%$ of self-carvers came from intact marriages while $37 \%$ had divorced parents. Twenty-nine percent stated that they had cut themselves only once or twice while $36 \%$ had done so at least 6 times. Rosen and Heard (1995) investigated SM in a group of adolescents attending a school for serious emotional problems. Results indicate that over the 4-year study period, 32 adolescents $(n=$ 26 females; $n=6$ males) reported self-mutilating an average number of 4 times. The majority of these acts were superficial $(86.7 \%)$ and no medical intervention was required. Only $4.7 \%$ of the injuries required a visit to the emergency room or a doctor's office. In another study, Walsh and Rosen (1988) examined life experiences in a group of 52 self-mutilating adolescents and 52 nonmutilators matched for sex and treatment program from
4 treatment settings serving adolescents. To be eligible for the self-mutilation group, participants had to have selfmutilated while in care and had to have been between the ages of 13-20 upon admission. The authors found that the self-mutilators were more likely to have experienced loss of a parent due to divorce, placement in foster care, or placement in group care. Finally, using hospital records, Simpson and Porter (1981) investigated several variables including age and type of mutilation in a sample of 20 ( $n=16$ females, $n=4$ males $)$ hospitalized children and adolescent self-mutilators. The average age of hospitalization for self-mutilative behavior was found to be 16 , although psychiatric difficulties seemed to be present earlier in the sample. In addition, although the majority of participants were periodically suicidal, none had intended to kill themselves by their mutilative behavior. Injuries were typically minor and consisted of small lacerations or burns. In sum, the studies from the clinical literature provide information regarding both characteristics of the sample as well as behavior patterns associated with the SM act. It is not known, however, whether similar findings would be obtained in a nonclinical sample of adolescents who self-mutilate.

Finally, the last group of studies have looked at SM across a wide age range. Hawton et al. (1997) investigated trends in DSH from 1985 to 1995, which was defined as "any injury recognized by hospital staff as having been deliberately self-inflicted" (p. 556). Results indicated a considerable increase in rates of DSH over the 11-year period, especially in the adolescent age groups. Among 15-24 year old males, there was a 194\% rise over time. In a frequently cited study, Favazza and Conterio (1989) examined female habitual self-mutilators. Two hundred and twenty-nine surveys were analyzed and the authors also included surveys from 25 psychiatric patients who had repeatedly self-mutilated. Twelve percent of the sample were students. Family data reveal that $29 \%$ of the women came from divorced families. Multiple methods of selfharm were used by $75 \%$ of the sample with the majority engaging in skin cutting (72\%), skin burning (35\%), and self-hitting $(30 \%)$. Fourteen was the common age that participants reported first engaging in SM. Finally, in a classic study, Rosenthal et al. (1972) examined 24 inpatient nonsuicidal wrist cutters aged 15-42 and 24 women with a history of suicide attempts other than self-cutting. The results reveal that the majority of self-mutilators first cut themselves in adolescence (mean age 16). No differences were found in the family background for both groups although both groups' childhood was characterized by abuse and broken homes.

Thus, findings from the research offer tentative evidence that SM may be becoming more prevalent among 
adolescents (Hawton et al., 1997). However, more research is needed to document the occurrence of SM in high school students. Only a few studies have examined the incidence of SM in adolescents and their findings are somewhat compromised by a lack of distinction between suicidal behavior and SM (Martin et al., 1995; Patton et al., 1997). These studies have focused on self-harm behaviors rather than SM per se, which has resulted in a paucity of information concerning the prevalence of SM in community samples of adolescents. Furthermore, there is an absence of information concerning demographic characteristics or patterns of SM in high school students. Typically, the research in this area has been conducted on clinical samples of adolescents who self-mutilate.

\section{SM, Anxiety, and Depression}

In an attempt to understand the social-affective dimensions of self-mutilation, researchers have become interested in examining whether a relationship exists between self-mutilation and depression and/or anxiety (Bennum, 1984; Brodsky et al., 1995; Burgess, 1991; Ennis et al., 1989; Herpetz, 1995). This premise is based on theories which posit that individuals may self-mutilate in order to reduce intolerable and negative feelings such as feelings of anxiety and/or depression (Bennum, 1984). Thus, anxiety and depression may function as precipitating factors in self-mutilation.

With respect to depression, there has been an assumption in the research that individuals who self-mutilate are depressed (Favazza, 1998; Feldman, 1988). This belief may be based in part on the finding that individuals who self-mutilate often report feeling sad or lonely prior to hurting themselves (Favazza and Conterio, 1989; Rosenthal et al., 1972). However, these studies have not empirically measured depression and instead have asked participants to recount what they were feeling prior to selfmutilating. Although another group of studies has measured levels of depression, the findings have been somewhat limited due to their reliance on samples composed primarily of adult psychiatric patients who have been diagnosed with borderline personality disorder (Brodsky et al., 1995; Dulit et al., 1994; Simeon et al., 1992). For example, Brodsky et al. (1995) administered the Hamilton Rating Scale for Depression (HRS-D) to 60 consecutively admitted female inpatients with borderline personality disorder. Fifty-two percent of the sample reported a history of self-mutilation. No significant differences were found between self-mutilators and nonmutilators on the Hamilton Rating Scale for Depression (HRS-D) with both groups scoring as severely depressed. Similarly, Dulit et al. (1994) examined several clinical correlates of self-mutilation, including depression in a sample of patients with borderline personality disorder. Out of 124 consecutively admitted patients with the disorder, $50 \%$ of the patients were found to have self-mutilated ( $n=62$ ). The groups did not differ on the HRS-D as both scored in the moderate range for depression. Bennum and Phil (1983) assessed depression in 20 self-mutilators ( $n=3$ males, $n=17$ females), 20 depressives, and 20 controls matched for age, sex, psychiatric diagnosis, and marital status. Using the Beck Depression Inventory (BDI), no significant differences in depression emerged between the self-mutilating group and the depressed group as both groups scored in the severe range. Finally, Simeon et al. (1992) attempted to determine whether self-mutilators with a personality disorder differed from nonmutilators with a personality disorder on measures of psychopathology, including depression. Twenty-six self-mutilators ( $n=20$ women; $n=6$ men) with a personality disorder were matched to 26 control participants with personality disorder who did not selfmutilate on age, gender, and axis I diagnosis of affective disorders. The BDI, the HRS-D, and the Beck Hopelessness Scale were also administered to assess depression. Results indicated that while self-mutilators had a higher mean depression score on the HRS-D as compared to the nonmutilating group, no differences were found between the groups on the BDI and the Beck Hopelessness Scale. Overall, these studies suggest that while depression may be commonly reported in patients who self-mutilate, it does not appear to differentiate psychiatric patients who self-mutilate from those who do not self-mutilate.

Only 1 study examined the link between depression and self-mutilation in a community sample of adolescents. In a study reported on earlier, Martin et al. (1995) administered the BDI to 352 high school students. The authors found that deliberate self-harm was associated with higher depression scores on the BDI. In sum, research on depression and SM suggests that depression may occur frequently among adult psychiatric patients who selfmutilate. However, it is not clear whether the depression is specific to SM or whether it is simply a reflection of mental health difficulties inherent in psychiatric populations. Thus, it is not surprising that a clinical population would be more at risk for other mental health problems including depression. What is less clear is whether community samples of adolescents who self-mutilate will also manifest a heightened risk for depression.

With respect to anxiety, few studies have assessed levels of anxiety in individuals who self-mutilate. Generally, the literature in this area is characterized by a reliance on accounts from individuals who self-mutilate (Favazza and Conterio, 1989). These individuals recall mounting feelings of anxiety and tension that develop prior to hurting 
themselves. For example, in a survey completed by 240 habitual female self-mutilators, Favazza and Conterio (1989) report that $72 \%$ of participants describe selfmutilating to control their mind and stop it from racing while $65 \%$ reported self-mutilating to feel relaxed. Similarly, in a study reported on earlier, Schwartz et al. (1989) noted that $27 \%$ of drug-abusing girls who self-mutilated reported feeling that they had temporarily diffused the build-up of tension after self-mutilating. Although these studies provide some evidence for the existence of anxiety in individuals who self-mutilate, there is an absence of research that assesses levels of anxiety and compares it to a control group made up of non-self-mutilating adolescents.

Thus, the purpose of the present study is to document the prevalence of SM in a community sample of high school students. In addition, demographic variables such as family structure, ethnicity, and gender will also be examined. Patterns of SM including the frequency of SM behavior, the methods used and the age of onset also will be explored. Finally, other mental health problems such as depression and anxiety will be examined in order to gain insight into the possible emotional factors related to self-mutilation.

\section{METHOD}

\section{Sample}

An urban and a suburban high school participated in the project. These 2 schools were targeted for the study in order to obtain a more representative estimate of the prevalence of SM. The urban school was composed of ethnically diverse students from mainly lower middle class homes. In contrast, students attending the suburban school were primarily Caucasian and came from upper-middle class homes. Specific information regarding SES and overall racial background of the student body was not made available by the schools. All Grades 7-11 students in the urban school were approached to participate (average age 14 years old) while in the suburban high school, only Grades 9 and 10 were approached (average age 15 years old). Grade 7 and 8 students were unavailable because of their participation in another project. A total of 440 students ( $n=231$ from the urban school; $n=209$ students from the suburban school) agreed to participate in the study (see Table I).

Students were classified as self-mutilators based on their responses on both an initial screening questionnaire and during a semistructured interview. Adolescents who endorsed an item asking them if they had ever hurt themselves on purpose were then selected to participate in
Table I. Breakdown of Screening Sample

\begin{tabular}{rlcc}
\hline Grade & High school & Boys $(N=219)$ & Girls $(N=221)$ \\
\hline 7 & Urban & 40 & 25 \\
8 & Urban & 20 & 20 \\
9 & Urban & 25 & 26 \\
10 & Urban & 21 & 23 \\
11 & Urban & 10 & 21 \\
9 & Suburban & 47 & 48 \\
10 & Suburban & 56 & 58 \\
\hline
\end{tabular}

an interview. The interview session served to clarify and evaluate whether the student could be classified as having self-mutilated. This decision was based on the use of a definition, articulated by Favazza (1989) whereby SM was considered to be any incident where an individual had attempted to deliberately alter or destroy body tissue without suicidal intent (i.e., cutting, burning, scratching, hitting, bitting, pinching). Based on this criteria, students who reported driving recklessly, taking drugs, mentally hurting themselves (e.g., putting themselves down) or engaging in other risky behaviors were not included in the self-mutilation group and were excluded from the study.

\section{MEASURES}

\section{Screening Questionnaire}

A screening questionnaire was designed and administered to all participants to assess the presence or absence of self-mutilative behavior. Because of concerns about suggestibility, the scale assessed SM by using 1 question that was embedded in a coping measure entitled "How I Deal with Stress" (see Appendix). This 24-item self-report questionnaire presented a list of strategies that adolescents may use to cope with stress and other difficulties. Using a 4-point Likert scale, students were asked to indicate whether they have used each strategy frequently, a couple of times, once or never. Items ranged from adaptive coping behaviors, such as talking to a friend and going for a walk to maladaptive coping behaviors such as drinking, fighting, and recklessness. The item assessing SM questioned students on whether they had ever hurt themselves on purpose. The instructions were read aloud by the examiner who began by telling students that the purpose of the questionnaire was to examine how adolescents cope with stress. Students were then asked to read through each item and to indicate whether they have ever used that response to cope with a stressful situation or a problem.

Although no validity and reliability information exists, the literature in this area is characterized by the use 
of informal questionnaires devised by authors to identify SM (Dulit et al., 1994; Favazza and Conterio, 1989; Patton et al., 1997; Schwartz et al., 1989; van der Kolk et al., 1991). In addition, open ended questions to assess self-mutilative behavior are widely used in the field (Martin et al., 1995; Schwartz et al., 1989; Taiminen et al., 1998; Walsh and Rosen, 1988).

\section{Semi-Structured Interview}

To confirm the existence of SM as well as to gather further information about the act, a semistructured interview was conducted. The 1st section was composed of questions that dealt with demographic information such as current family structure and who lives in the home. The 2nd part of the interview focused on self-mutilation. First, students were asked to elaborate on what they meant by "hurting themselves on purpose." Students who described an incident of SM were then asked questions regarding the methods they used to self-mutilate. In addition, students were questioned regarding how frequently they selfmutilated. Finally, questions were asked pertaining to the age that they began self-mutilating. The $3 \mathrm{rd}$ part of the interview dealt more with affect both prior to, during, and after self-mutilating. More specifically, the students were encouraged to discuss how they had been feeling prior to hurting themselves. The researcher probed for an affective description of the adolescents emotional state leading up to the self-mutilation and during the self-mutilation. An attempt was made to elicit information about whether the adolescent felt sad, lonely, anxious, tense, and/or unhappy right before they self-mutilated or while they were selfmutilating. This information was designed to complement the standardized questionnaire in order to provide more qualitative information regarding depression, anxiety, and overall mood.

\section{Beck Depression Inventory}

The Beck Depression Inventory (BDI; Beck and Steer, 1993b) was used to provide a measure of depressive symptomatology. The BDI is one of the most widely used self-report measures of adult and adolescent depressive symptomatology (Reynolds, 1994). The scale measures cognitive, affective, motivational vegetative, and physical manifestations of depression. It consists of 21 items, with each item consisting of 4 statements which are ranked from 0 to 3 indicating symptom severity. Scores range from 0 to 63 with higher scores indicating the presence of depressive symptomatology. Four cutoff points indicate severity of depression (0-9 - non depressed; 10-15 mild depression; 16-23 - moderate depression; 24-63 severe depression; Beck and Steer, 1993b). An overall cutoff score of 16 resulted in high sensitivity (100\%) and specificity (93.2\%) of a sample of high school adolescents (Barrera and Garrison-Jones, 1988).

The BDI has been shown to successfully differentiate between depressed and nondepressed persons (Kauth and Zettle, 1990) and to possess strong psychometric properties (Barrera and Garrison-Jones, 1988; Larsson and Melin, 1990). Internal consistency coefficients of the BDI have been reported to range from 0.78 to 0.90 and testretest reliability coefficients range from 0.74 to 0.98 depending on the intervals between testing (Ambrosini et al., 1991; Larsson and Melin, 1990). This measure has also good discriminant and convergent validity (Barrera and Garrison-Jones, 1988). It has been successfully used with nonclinical populations of adolescents (Friedrich et al., 1988; Larsson and Melin, 1990). It has been found to be an effective screening device for depressive symptomatology for adolescents samples (Kashani et al., 1990).

\section{Beck Anxiety Inventory}

The Beck Anxiety Inventory (BAI; Beck and Steer, 1993a; Beck et al., 1988) was used to provide a measure of anxiety. The scale is a brief self-report inventory that is designed to assess symptoms of anxiety, which are minimally shared with depression. The scale's creators have attempted to overcome the limitations of other self-report measures of anxiety such as the State-Trait Anxiety Inventory and the Revised Children's Manifest Anxiety Scale, which purportedly measure symptoms of depression as well as anxiety (Endler et al., 1992). The BAI consists of 21 items that are rated for severity on 4-point Likert scale (0-3) ranging from "Not at all" to "Severely, I could barely stand it." Of the total items, 14 represent somatic symptoms while 7 assess specific cognitive and subjective features of anxiety. The items are added up to provide a total score. Scores range from 0 to 63 with scores from 0 to 7 falling within the normal range, scores from 8 to 15 indicate mild anxiety, scores from 16 to 25 reflect moderate anxiety and scores from 26 to 63 indicate severe anxiety (Beck et al., 1988).

The BAI has been successfully used with both clinical and nonclinical groups (Clarke et al., 1994). Internal consistency reliability coefficients have been reported to range from 0.85 to 0.94 while test-retest reliability coefficients were 0.75 over a 1-week period (Beck et al., 1988; Wetherell and Arean, 1997). The scale has also demonstrated adequate to excellent concurrent, construct, 
and discriminant validity (Clarke et al., 1994). The factor structure of the BAI has been investigated in both clinical (Beck et al., 1988; Wetherell and Arean, 1997) and nonclinical samples with most studies demonstrating two factors measuring physiological symptoms of anxiety and cognitive/subjective symptoms of anxiety (Steer, 1997).

\section{PROCEDURE}

All potential participants met with the researcher initially in classes. Six hundred and sixty-three consent forms were distributed to the students and because students were minors, consent letters were also sent home to the parents. To participate in the project, students had to consent and then return the other letter signed by their parent or guardian. Ninety-one percent of students agreed to participate in the project. Of that number, $73 \%$ returned both consent letters $(n=440)$. In addition, at this meeting, all potential participants were told that the purpose of the study was to examine how adolescents deal with stress. The confidentiality of their responses was emphasized and exceptions to confidentiality were discussed.

Participants were seen in 3 sessions. In the 1st session, consenting students took part in the screening phase of the study. Students were taken out of classes and given the screening questionnaire "How I Deal with Stress" to complete. Students who indicated that they hurt themselves on purpose were identified. A comparison group matched for grade, gender, and ethnicity was then randomly selected. In the 2nd session, both the group of selfmutilators and the comparison were taken out and were given the BAI. Finally, in the last session, students who had indicated that they self-harmed were taken out individually and were administered the BDI. Because of potential reading difficulties, the researcher read aloud the BDI to the student. Next, students were asked to describe examples of "hurting themselves on purpose." Students who met the criteria for SM then underwent the interview.

\section{RESULTS}

A total of 440 screening questionnaires were filled out in both schools. In the urban school, 231 students completed the screening questionnaire of which $21.2 \%(n=$ 49 ) indicated that they had hurt themselves on purpose. Following the interview, a total of $13 \%$ of the students $(n=30)$ could be categorized as having self-mutilated ( $n=2$ students in Grade 11, $n=10$ students in Grade 10, $n=4$ students in Grade 9, $n=6$ students in Grade 8, and $n=8$ students in Grade 7). Similarly, in the sub- urban school, out of the 209 participating students, $19.6 \%(n=41)$ indicated that they had hurt themselves on purpose. After the interview, $14.8 \%(n=31)$ of the students were classified as having self-mutilated $(n=$ 14 students in Grade 9, $n=17$ students in Grade 10). Three students, however, were not interviewed because of repeated absenteeism. To examine whether the schools differed in terms of the prevalence of SM, a chi-square analysis was conducted. Results indicated no significant differences between the schools in terms of the prevalence of SM. Therefore, the samples were combined and their prevalence rate averaged. Thus, an overall prevalence rate of $13.9 \%(n=61)$ was obtained for both samples.

\section{Sample Characteristics}

Demographic information was obtained from the sample of students who self-mutilated in terms of cultural diversity, family structure, and gender. In terms of ethnic/racial composition, $77 \%(n=47)$ of the sample who SM were Caucasian, $5 \%(n=3)$ were Black, $6.5 \%(n=4)$ were Asian, $3.3 \%(n=2)$ were Hispanic, and $8.2 \%(n=5)$ were classified as Other Minority. Of the students who self-mutilated, $59 \%(n=36)$ came from homes where parents were married, $36 \%(n=22)$ came from divorced/separated homes and 5\% $(n=3)$ had parents who were widowed. Finally, gender differences in the prevalence of SM were also examined. Results indicate that of the adolescents who self-mutilated, $64 \%$ were girls $(n=39)$ and $36 \%$ were boys $(n=22)$. A chi-square analysis was conducted in order to examine whether there were any gender differences in the prevalence of the SM. Results were found to be significant, $\chi^{2}(1, n=61)=$ 4.7377, $p<0.05$, indicating that girls were significantly more likely to self-mutilate as compared to boys.

\section{Self-Mutilative Practices}

In terms of self-mutilative practices, $16.4 \%$ of the sample $(n=10)$ reported using more than 1 method to self-mutilate while $83.6 \%(n=51)$ indicated using only 1 method. Skin cutting ( $41 \% ; n=25)$ was the most common practice followed by self-hitting $(32.8 \% ; n=20)$, pinching $(6.5 \% ; n=4)$, scratching $(5 \% ; n=3)$, biting $(5 \% ; n=3)$, and burning $(3.3 \% ; n=2)$. In addition, $18 \%$ of the sample $(n=11)$ reported punching or hitting a wall.

In terms of the frequency of the behavior, $13.1 \%$ ( $n=$ 8 ) of the SM group reported self-mutilating more than once a day, $27.9 \%(n=17)$ said they self-mutilated a 
couple of times a week, $19.6 \%(n=12)$ self-mutilated a couple of times a month, $18 \%(n=11)$ had self-mutilated on only one occasion, and $19.6 \%(n=12)$ described selfmutilating episodically. In terms of current practice, $64 \%$ of the sample $(n=39)$ reported that they no longer self-mutilate. Of the students who still self-mutilate, $36.3 \%(n=8)$ say they hit themselves, $27.3 \%(n=6)$ describe punching walls and $9.1 \%(n=2)$ report cutting. Finally, in terms of age of onset, $11.5 \%(n=7)$ described starting to self-mutilate during Grade $9,59 \%$ of the sample $(n=36)$ began self-mutilating in Grade 7 and/or 8 , $24.6 \%(n=15)$ stated they started in Grade 6 or younger, and $4.9 \%(n=3)$ could not remember when they started engaging in the behavior.

\section{Anxiety and Depressive Symptomatology}

In order to assess for the presence of anxiety and depressive symptomatology, a two (gender) $\times$ two $(\mathrm{SM} /$ non-SM) Multivariate Analysis of Variance (MANOVA) was conducted with gender and SM serving as independent variables and mean BDI and BAI scores serving as the dependent variables. A significant SM effect was uncovered (Wilk's $\lambda=0.843 ; F(2,115)=10.73, p<0.001)$. There was an overall difference in terms of anxiety and depression between adolescents who self-mutilate and those who do not self-mutilate. No other significant differences were found.

In order to explore the source of differences in anxiety and depression between the groups, follow-up univariate tests were conducted. Univariate $F$ tests were performed to test for an effect of SM/Non-SM on both the BDI and BAI. The main effect for SM was found to be significant for both depression $(F(1,116)=21.380, p<0.001)$ and anxiety $(F(1,116)=11.331, p<0.01)$. That is adolescents who have self-mutilated reported significantly more depressive symptomatology and greater anxiety as compared to adolescents who do not self-mutilate when both the BDI and BAI are considered independently. In addition, 64\% ( $n=36 / 61$ ) of the students who self-mutilated used terms such as "lonely" "sad," and "alone" to describe what they had been feeling prior to and during self-mutilating.

\section{DISCUSSION}

The results of this study suggest that SM may be a prevalent problem affecting today's youth. Although the student populations in the 2 schools differed in terms of ethnicity and socioeconomic status, the rates of SM reported were similar. This finding suggests that self- mutilation may be becoming an increasingly widespread behavior among adolescents. An average of $13.9 \%$ of high school students report self-mutilating at least once. The prevalence rate obtained in the present study is consistent with results reported by Favazza et al. (1989) in their study of SM using university students. While studies that have examined self-harm behavior including SM have typically reported lower rates than was found in the present investigation, students were often required to limit their reporting of SM to the past year (Patton et al., 1997). Further, these studies have often measured a group of nonspecific selfharm behaviors where suicidal behavior, risky behaviors, and SM have not been clearly differentiated.

Present results from the study highlight the importance of using both a screening measure and an interview format to obtain reliable estimates of SM as distinct from other self-harming behaviors. More specifically, a prevalence rate of $21.2 \%$ in the urban school and $19.6 \%$ in the suburban school was noted following the administration of the screening questionnaire. However, by probing students' responses during the interview it was determined that many adolescents engaged in other behaviors that could not be categorized as self-mutilation such as mentally hurting oneself or risk taking. The behaviors described appeared to fall into a general category of selfharming behaviors. These findings underscore the need to employ multiple measures when documenting SM.

The study also examined demographic characteristics of the sample. In terms of ethnicity, results indicate that a large percentage of students who self-mutilated were Caucasian, even in the urban school. This finding was surprising in light of the large proportion of ethnically diverse students attending the urban high school. Unfortunately, information concerning ethnicity of the student population as a whole was not available to the researcher and thus, it is not known whether the students who self-mutilated differed significantly in terms of ethnicity from the school population.

Further, the present study found evidence that girls are more likely to self-mutilate as compared to boys. Although this finding is consistent with studies using clinical populations of adolescents (Pattison and Kahan, 1983), the handful of studies that have investigated self-harm in community samples of high school students have reported mixed results with some studies citing gender differences (e.g., Patton et al., 1997) and some reporting none (e.g., Martin et al., 1995). One possibility for this discrepancy in the nonclinical literature may be derive in part from the way that self-harm is defined by the researchers. For example, some researchers have included deliberate recklessness, risk taking, and self-poisoning as part of their definitions. The inconsistency of using different behaviors 
to measure self-mutilation may result in findings of gender differences in some cases while not in others. For example, boys may be more likely to engage in risk taking behaviors while girls may be more likely to self-cut. Findings from the present study suggest that when a definition of SM specifies a deliberate attempt to alter or destroy body tissue without suicidal attempt, girls may be more likely than boys to engage in this type of behavior. These gender differences may reflect the differential coping behaviors that males and females use to deal with stress. In fact, one prominent theory of SM is that the act represents an attempt to relieve overwhelming affect such as anger (Favazza, 1998; Pattison and Kahan, 1983; Bennum, 1984). Given that the outward expression of anger may be less socially acceptable for girls than it is for boys, girls may become more likely to direct their anger inwards onto themselves, which results in a pattern of SM behavior. Additional research is needed to explore the reasons for SM behaviors in adolescents in order to gain a greater understanding of gender differences in SM.

Overall, the majority of adolescents report using only 1 method to self-mutilate. Further, results indicate that the most frequent methods of SM among adolescents are selfcutting and self-hitting. This result is consistent with other studies which report that self-cutting is the most common method (Favazza and Conterio, 1989; Herpertz, 1995). It is important to note that there appears to be a group of adolescents who hit walls or objects. Although this group of students may "fit" into the current conceptualization of SM, it is not clear whether this group is clinically similar to adolescents who hit or punch themselves. In interviews with these students, many disclosed that they hit or punched the wall as a means of expressing their anger towards others. They often stated that they were unable to hit the person who angered them and would instead direct their anger onto an object. In contrast, students who self-hit describe feelings of self-hatred or sadness and frequently mention being angry at themselves or feeling the need to punish themselves. Further research is needed to explore whether these 2 groups are distinct both clinically and empirically.

In terms of the frequency of SM, no one pattern could characterize the sample. Some students engaged in the behavior daily while others self-mutilated only once. In contrast to the clinical literature where repeated episodes of SM may occur (Rosen and Heard, 1995), results indicate wide variation in terms of the frequency of the behavior among high school students. A considerable proportion of students also stated that they no longer self-mutilate. Taken together these findings suggest that for many students, self-mutilation represents a temporary behavior that is engaged in for a limited period. One hypothesis is that some students experiment with SM in order to deal with specific stressful life events. Once the situations are resolved, the adolescent may no longer feel the need to selfmutilate. However, a smaller percentage of students may continue to engage in the behavior due to more chronic stressors or emotional difficulties. Additional research is needed to explore the etiological underpinnings of SM in normative samples of adolescents.

Finally, using a self-report questionnaire, students who self-mutilate were found to report greater levels of anxiety and depressive symptomatology, regardless of gender. Prior research has often found no differences in depression between adult psychiatric patients who selfmutilate and those patients who do not self-mutilate as both groups report equally high levels of depression. However, these findings may simply reflect an increased preponderance of global psychopathology which characterizes psychiatric populations. In contrast, the current finding suggests increased levels of depressive symptomatology may differentiate adolescents who self-mutilate from those who do not engage in the behavior. In addition, the present study also found higher levels of anxiety in adolescents who self-mutilate. Previous research has often relied on anecdotal accounts by self-mutilators and has not typically compared levels of anxiety in individuals who self-mutilate to individuals who do not self-mutilate.

Taken together, the findings on depression and anxiety suggest that greater socioemotional difficulties may be present in adolescents who self-mutilate. Given that many students were no longer hurting themselves, the results suggest that this group of adolescents may still be vulnerable to increased mental health difficulties. One possibility is that self-mutilation functions as an unorthodox means of controlling feelings of tension and/or sadness that arise out of a stressful environment (Bennum, 1984). This explanation is consistent with anxiety reduction models of self-mutilation, which can be helpful ways of conceptualizing and possibly treating SM behavior. With respect to the current findings, treatment centers on alleviating the underlying depression and providing the adolescent with a set of more adaptive and alternative strategies to help them cope with negative affect. Further, there is an increased focus on teaching stress management techniques that may help the adolescent deal with feelings of tension and anxiety. Thus, the present study provides initial documentation that feelings of depression and anxiety may occur comorbidly with self-mutilation.

One limitation of the present study is that because the schools did not provide information regarding the ethnic composition of the students, it was not possible to investigate whether the ethnicity of the students who selfmutilated differed significantly from the population of the 
school as a whole. Despite this limitation, this study provides empirical documentation concerning the frequency of a behavior that is receiving considerable attention in the popular culture (e.g., the movie "Girl Interrupted," the television show "Big Brother"). It is of significance that this behavior is occurring in more than $1 / 10$ of high school students. This prevalence is surprising given the normative nature of the population and serves to alert practitioners to the extent of SM behaviors in high schools. Future research is needed to explore possible reasons why adolescents self-mutilate. More specifically, the clinical research has focused on factors such as abuse both physical and/or sexual. It is not clear whether these factors would also present in community samples of adolescents. The relationship between school/academic stress also warrant further attention. Further information regarding possible stressors may help practitioners focus their attention and resources.

\section{APPENDIX: HOW I DEAL WITH STRESS}

Adolescents have to deal with a lot of stress. In a recent survey, adolescents said they used the following list of strategies to help them deal with problems. We are interested if you also used any of these strategies to help you deal with stress. Please read each item and indicate whether you

have never used this strategy (0),

have used this strategy only once (1),

have used this strategy a couple of times to cope with stress (2), and

have frequently used this strategy to cope with stress (3).

There are no right or wrong answers.

\begin{tabular}{|c|c|c|c|c|}
\hline & Never & Once & $\begin{array}{l}\text { Couple } \\
\text { of times }\end{array}$ & Frequently \\
\hline 1. Try not to think about it & 0 & 1 & 2 & 3 \\
\hline 2. Spend time alone & 0 & 1 & 2 & 3 \\
\hline 3. Go out & 0 & 1 & 2 & 3 \\
\hline $\begin{array}{l}\text { 4. Talk to someone } \\
\text { (friend, parents, etc) }\end{array}$ & 0 & 1 & 2 & 3 \\
\hline 5. Try to solve the problem & 0 & 1 & 2 & 3 \\
\hline $\begin{array}{l}\text { 6. Do something to keep } \\
\text { busy }\end{array}$ & 0 & 1 & 2 & 3 \\
\hline $\begin{array}{l}\text { 7. Say to myself it doesn't } \\
\text { matter }\end{array}$ & 0 & 1 & 2 & 3 \\
\hline 8. Listen to music & 0 & 1 & 2 & 3 \\
\hline 9. Exercise & 0 & 1 & 2 & 3 \\
\hline 10. Play sports & 0 & 1 & 2 & 3 \\
\hline 11. Read & 0 & 1 & 2 & 3 \\
\hline
\end{tabular}

\begin{tabular}{lcccc}
\multicolumn{4}{c}{ APPENDIX: (Continued) } \\
\hline & Never & Once & $\begin{array}{c}\text { Couple } \\
\text { of times }\end{array}$ & Frequently \\
\hline 12. Go shopping & 0 & 1 & 2 & 3 \\
13. Eat & 0 & 1 & 2 & 3 \\
14. Stop eating & 0 & 1 & 2 & 3 \\
15. Drink & 0 & 1 & 2 & 3 \\
16. Hit someone & 0 & 1 & 2 & 3 \\
17. Get into an argument & 0 & 1 & 2 & 3 \\
$\quad$ with someone & & & & \\
18. Do drugs & 0 & 1 & 2 & 3 \\
19. Smoke & 0 & 1 & 2 & 3 \\
20. Do risky things & 0 & 1 & 2 & 3 \\
21. Hurt myself on purpose & 0 & 1 & 2 & 3 \\
22. Cry & 0 & 1 & 2 & 3 \\
23. Sleep & 0 & 1 & 2 & 3 \\
24. Other & & & & \\
\hline
\end{tabular}

\section{REFERENCES}

Ambrosini, P. J., Metz, C., Bianchi, M. D., Rabinovich, H., and Undie, A. (1991). Concurrent validity and psychometric properties of the Beck Depression Inventory in outpatient adolescents. J. Am. Acad. Child Adolesc. Psychiatry 30: 51-57.

Barrera, M., and Garrison-Jones, C.V. (1988). Properties of the Beck Depression Inventory as a screening measure for adolescent depression. J. Abnorm. Child Psychol. 16: 263-273.

Beck, A. T., Epstein, N., Brown, G., and Steer, R. A. (1988). An inventory for measuring clinical anxiety. Psychometric properties. J. Consult. Clin. Psychol. 56: 893-897.

Beck, A. T., Schuyler, D., and Herman, J. (1974). Development of the Suicide Intent Scales. In Beck, A. T., Resnick, H. L. P., and Lettieri, D. J. (eds.), Prediction of Suicide. Charles Press, New York, pp. 5456.

Beck, A. T., and Steer, R. A. (1993a). Manual for the Beck Anxiety Inventory. Psychological Corporation, San Antonio.

Beck, A. T., and Steer, R. A. (1993b). Manual for the Beck Depression Inventory. Psychological Corporation, San Antonio.

Bennum, I. (1984). Psychological models of self-mutilation. Suicide Life Threat. Behav. 14: 166-186.

Bennum, I., and Phil, M. (1983). Depression and hostility in selfmutilation. Suicide Life Threat. Behav. 13: 71-84.

Brittlebank, A. D., Cole, A., Hassanyeh, F., Kenny, M., Simpson, D., and Scott, J. (1990). Hostility, hopelessness and deliberate self-harm: A prospective follow-up study. Acta Psychiatr. Scand. 81: 280283.

Brodsky, B. S., Cloitre, M., and Dulit, R. A. (1995). Relationship of dissociation to self-mutilation and childhood abuse in borderline personality disorder. Am. J. Psychiatry 152: 17881792.

Brooksbank, D. J. (1985). Suicide and parasuicide in childhood and early adolescence. Br. J. Psychiatry 146: 459-463.

Burgess, J. W. (1991). Relationship of depression and cognitive impairment to self-injury in borderline personality disorder, major depression and schizophrenia. Psychiatr. Res. 38: 77-87.

Clarke, L. A., Steer, R. A., and Beck, A. T. (1994). Common and specific dimensions of self-reported anxiety and depression: Implications for the cognitive and tripartite models. J. Abnorm. Psychol. 103: $645-654$.

Dulit, R. A., Fryer, M. R., Leon, A. C., Brodsky, B. S., and Frances, A. J. (1994). Clinical correlates of self-mutilation in borderline personality disorder. Am. J. Psychiatry 151: 1305-1311. 
Endler, N. S., Cox, B. J., Parker, J. D., and Bagby, R. M. (1992). Selfreport of depression and state-trait anxiety: Evidence for differential assessment. J. Pers. Soc. Psychol. 63: 832-838.

Ennis, J., Barnes, R. A., Kennedy, S., and Trachtenberg, D. (1989). Depression in self-harm patients. Br. J. Psychiatry 154: 41-47.

Favazza, A. R. (1998). The coming of age of self-mutilation. J. Nervous Ment. Dis. 186: 259-268.

Favazza, A. R. (1989). Why patients self-mutilate. Hosp. Comm. Psychiatry 40: 137-145.

Favazza, A. R., and Conterio, K. (1989). Habitual female self-mutilators. Acta Psychiatr. Scand. 79: 283-289.

Favazza, A. R., DeRosear, L., and Conterio, K. (1989). Self-mutilation and eating disorders. Suicide Life Threat. Behav. 19: 352-361.

Favazza, A. R., and Rosenthal, R. J. (1993). Diagnostic issue in selfmutilation. Hosp. Comm. Psychiatry 44: 134-141.

Feldmen, M. D. (1988). The challenge of self-mutilation: A review. Compr. Psychiatry 29: 252-269.

Friedrich, W. N., Reams, R., and Jacobs, J. H. (1988). Sex differences in depression in early adolescence. Psycholog. Rep. 62: 475481.

Hawton, K., and Fagg, J. (1992). Deliberate self-poisoning and selfinjury in adolescents: A study of the characteristics and trends in Oxford, 1976-1989. Br. J. Psychiatry 161: 816-823.

Hawton, K., and Fagg, J. (1992). Trends in deliberate self-poisoning and self-injury in Oxford, 1976-1990. BMJ 304: 1409-1411.

Hawton, K., Fagg, J., and Simkin, S. (1996). Deliberate self-poisoning and self-injury in children and adolescents under 16 years of age in Oxford, 1976-1993. Br. J. Psychiatry 169: 202-208.

Hawton, K., Fagg, J., Simkin, S., Bale, E., and Bond, A. (1997). Trends in deliberate self-harm in Oxford, 1985-1995. Br. J. Psychiatry 171: $556-560$.

Herpertz, S. (1995). Self-injurious behavior: Psychopathological and nosological characteristics in subtypes of self-injurers. Acta Psychiatr. Scand. 91: 57-68.

Kashani, J. H., Sherman, D. D., Parker, D. R., and Reid, J. C. (1990). Utility of the Beck Depression Inventory with clinic-referred adolescents. J. Am. Acad. Child Adolesc. Psychiatry 29: 278282.

Kauth, M. R., and Zettle, R. D. (1990). Validation of depression measures in adolescent populations. J. Clin. Psychol. 46: 291-295.

Larsson, B., and Melin, L. (1990). Depressive symptoms in Swedish adolescents. J. Abnorm. Child Psychol. 18: 91-103.

Lena, S. M., and Bijoor, S. (1990). Wrist cutting: A dare game among adolescents. Can. Med. Assoc. J. 142: 131-132.

Martin, G., Rozanes, P., Pearce, C., and Allison, S. (1995). Adolescent suicide, depression and family dysfunction. Acta Psychiatr. Scand. 92: 336-344.

McLaughlin, J., Miller, P., and Warwick, H. (1996). Deliberate self-harm in adolescents: Hopelessness, depression and problem-solving. J. Adolesc. 18: 523-532.

Pattison, E. M., and Kahan, J. (1983). The deliberate self-harm syndrome. Am. J. Psychiatry 140: 867-872.
Patton, G. C., Harris, R., Carlin, J. B., Hibbert, M., Coffey, C. Schwartz, M., and Bowes, G. (1997). Adolescent suicidal behaviors: A population based study of risk. Psychol. Med. 27: 715-724.

Pipher, M. (1994). Reviving Ophelia. Ballantine Books, New York.

Reynolds, W. M. (1994). Assessment of depression in children and adolescents by self-report questionnaires. In Reynolds, W. M., and Johnston, H. F. (eds.), Handbook of Depression in Children and Adolescents. Plenum Press, New York, pp. 209-244.

Rosen, P. M., and Heard, K. V. (1995). A method for reporting self-harm according to level of injury and location on the body. Suicide Life Threat. Behav. 25: 381-385.

Rosen, P. M., Walsh, B. W., and Rode, S. A. (1990). Interpersonal loss and self-mutilation. Suicide Life Threat. Behav. 20: 177-184.

Rosenthal, R. J., Rinzler, C., Wallsh, R., and Klausner, E. (1972). Wristcutting syndrome: The meaning of the gesture. Am. J. Psychiatry 128: 47-52.

Schwartz, R. H., Cohen, P., Hoffman, N. G., and Meeks, J. E. (1989). Self-harm behaviors (carving) in female adolescent drug abusers. Clin. Pediatrics 28: 340-346.

Scott, S. W., and Powell, J. C. (1993). Adolescent self-mutilation in a rural area. J. Adolesc. 16: 101-105.

Shearer, S. L. (1994). Phenomenology of self-injury among inpatient women with borderline personality disorder. J. Nervous Ment. Dis. 182: 524-526.

Simeon, D., Stanley, B., Frances, A., Mann, J. J., Winchel, R., and Stanley, M. (1992). Self-mutilation in personality disorders: Psychological and biological correlates. Am. J. Psychiatry 149: 221227.

Simpson, C. A., and Porter, G. L. (1981). Self-mutilation in children and adolescents. Bull. Menninger Clin. 45: 428-438.

Solomon, Y., and Farrand, J. (1996). "Why don't you do it properly?" Young women who self-injure. J. Adolesc. 19: 111-119.

Steer, R. A. (1997). Beck Anxiety Inventory. In Zalaquett, C. P., and Wood, R. J. (eds.), Evaluating Stress: A Book of Resources. The Scarecrow Press, London, pp. 23-40.

Taiminen, T. J., Kallio-Soukainen, K., Nokso-Koivisto, H., Kaljonen, A., and Helenius, H. (1998). Contagion of deliberate self-harm among adolescent inpatients. J. Am. Acad. Child Adolesc. Psychiatry 37: 211-217.

Tantam, D., and Whittaker, J. (1992). Personality disorder and selfwounding. Br. J. Psychiatry 161: 451-464.

van der Kolk, B. A., Perry, J. C., and Herman, J. L. (1991). Childhood origins of self-destructive behavior. Am. J. Psychiatry 148: 16651671

Walsh, B. W., and Rosen, P. M. (1988). Self-Mutilation: Theory, Research and Treatment. The Guilford Press, New York.

Wetherell, J. L., and Arean, P. (1997). Psychometric evaluation of the Beck Anxiety Inventory with older medical patients. Psychol. Assessment. 9: 136-144.

Winchel, R. A., and Stanley, M. (1991). Self-injurious behavior: A review of the behavior and biology of self-mutilation. Am. J. Psychiatry 148: 306-316. 